\title{
Development of Worldwide Tsunami Hazard Map for Evacuation Planning and Rescue Operations
}

\author{
Jais Jose $^{1 *}$, Yuvaraj ${ }^{1}$, Aswin S ${ }^{1}$, Arjun Suresh ${ }^{2}$ \\ 1.Amity Institute of Geoinformatics and Remote Sensing \\ 2.Amity Institute of Environmental Science \\ Email: jaiskattupalam@gmail.com
}

\begin{abstract}
The world tsunami hazard map is developed to understand the pattern of occurrence of tsunami across the globe and for using this database for preparing effective evacuation plan and rescue operations. It has been developed by using Web GIS tools. HTML, CSS, Java Script, JQuery, IIS and Maps API are utilized to develop hazard map. These data can be even used by government authorities as well as by other nodal agencies.
\end{abstract}

Key Words: Tsunami hazard map, Maps API, HTML, JavaScript, JQuery.

\section{INTRODUCTION}

Tsunami is a higher altitude water wave which is created due to the movement of tectonic plates and earthquakes of minimum 6.5 Magnitude and above. The subduction zone is the most vital region on Earth where the crash of plates and sinking of one plate underneath the other, resulting tsunami. In correlation with the magnitude of seismic movement, Tsunami can be classified into ruinous and non- damaging. Recent tsunamis comprehending the 2004 Indian Ocean locale, with in excess of 230,000 harmed and the tidal wave in Tohoku Japan 2011 , in excess of 18,500 individuals were missing or kicked the bucket. These are the two noteworthy damaging tsunamis that happened as of late in the middle of the years 2000 and 2018. In reporter to the tsunami that occurred in 2004 the administration of India took up crafted by setting up an Early Warning System for Tsunamis and now it's worked by the Indian National Center for Ocean Information Services (INCOIS)[1].Nowadays it's exceptionally valuable for foreseeing tsunamis and salvage tasks. A web based tsunami map must be done with multiple criteria approach coincides with the assessment site. The parameters considered were latitude, longitude, focal depth, event name, designator, region name, magnitude (initial), magnitude ( $\mathrm{Mw}$ ) and origin time (UTC).

This web based application is allowed to see the earthquake happened all over the world and providing the details of earthquake in a single click. Also provides the latest earthquake occurred within 7 days with details like magnitude of the earthquake, date and origin time, location, depth and direct link to USGS web page for further details. The ultimate web based map has good for the observation of earthquakes and historical data.[2] The purpose of this work is to analyze the historical data of earthquakes and tsunami risk maps required by the legislature and the individuals to comprehend whether their region is tsunami inclined or not. This tsunami hazard map can be valuable for the leaders for salvage exercises at the hour of tsunami. Many research and investigation has been done about the tsunami calamity map for just a specific region and those are not easy to understand but rather in this paper inspected about developing earthquake hazard map website page everywhere throughout the world and the clients can utilize the map as their prerequisite.

\section{MATERIALS AND METHODS}

\section{STUDY AREA}

The present investigation concentrated on the different earthquakes that happened everywhere throughout the world during the timespan from 1976 January 1 to 2019 June 12. Areas of 189 seismic tremors that happened during the investigation time frame are plotted on Google Earth.[5]

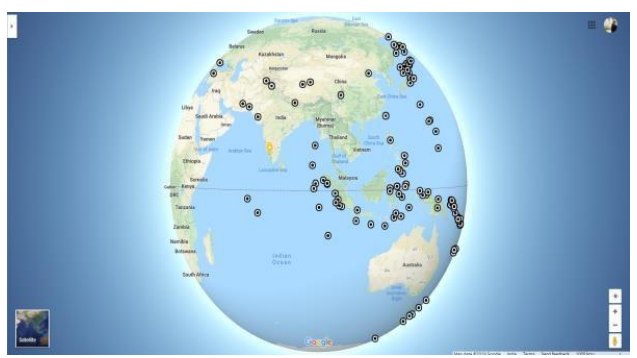

Fig 1. 3D representation of earthquakes occurred during the study period.

\section{METHODOLOGY}

\section{Earthquakes Data Collection}

The complete data separated from CMT Global search and the information taken from 1976 January 1 to 2019 June 12. Thereafter, the gathered information imported to the Microsoft Excel sheet and saved it as a comma separated value (CSV) document and the CSV record imported to the website page using HTML code [8].

\section{Creating Maps Java Script API}

Google Maps API key created from Google Cloud Platform Console and added the Map API key to Java Script code of Google Map along with latitude and longitude of the places of earthquakes occurred. 


\section{Creating a Webpage using HTML, JAVA Script, CSS, JQuery}

Created a webpage using HTML, JAVA Script, CSS, JQuery and it included 3 earthquake data table. The table data called GMT Psvelomeca consists of parameters like Longitude, Latitude, Str1, Dip1, Rake1, Str2, Dip2, Rake2, Sc, iexp, and Name. The third table known as GMT Psmeca and it includes the fields are Longitude, Latitude, Depth, Mrr, Mtt, Mpp, Mrt, Mrp, Mtp, and Iexp. It's a user friendly web page and the users can connect the administrator through the social media platforms like Facebook, Twitter, Google. Users can also vote for the improvement of webpage according to their experience using Yes or No button.

\section{Configuring Internet Information Services (IIS)}

The final step was configuring Internet Information Services (IIS) and created a virtual directory then hosted the webpage.

\section{RESULT AND DISCUSSION}

By analyzing the developed web page we can see that the earthquake is happening frequently in Ring of fire region. The ring of fire is always active in one area or another [3]. This ring is affected by active volcano that's why it is called Ring of fire'. Plate tectonics is responsible for the volcanic processes in this region. If we look at the map of the major plates (North American plate, South American plate, Pacific Ocean plate, Eurasian plate, African plate \& Indo-Australian plate ), and study about the concept of 'Plate tectonics' we can easily figure out the countries situated in the _Ring of fire' and we can also see that on the map[6].

The second prominent belt is Alpide earthquake belt lengthen from Java to Sumatra through the Himalayas, the Mediterranean, and out into the Atlantic where about 17 percent of earthquakes happen. The third belt follows the submerged mid-Atlantic Ridge and the remaining shakes are sprinkled in variegated areas of the world[4]. There are 3 tables in the website page and in the wake of dissecting the table present in the site page, it gives us a brief idea regarding the seismic tremors happened everywhere throughout the world and this table might be valuable for examining the quake information in the future.[7]

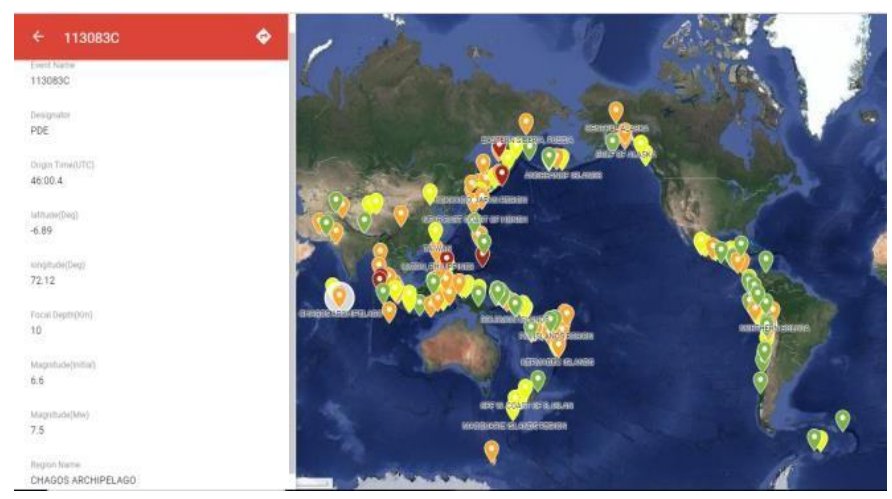

Fig.2 Details of earthquake

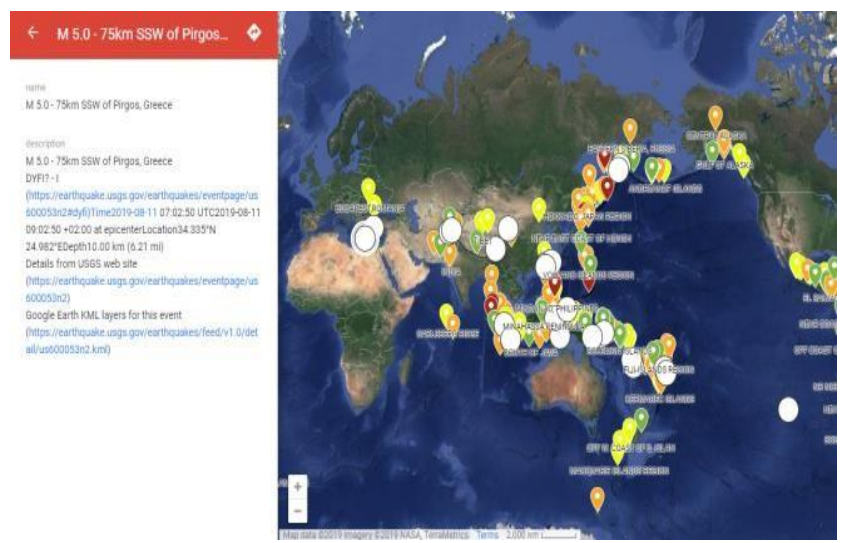

Fig.3 Latest earthquakes from USGS website.

Users can understand without much of a stretch recognize what all the seismic tremors are major and minor dependent on the shading given to the symbol and the color related to the magnitude are Red (7.2 - 8.9), Orange ( $6.6-7.1)$, Yellow $(6.0-6.5)$ and Green $(0.0-5.9) .[9][10]$

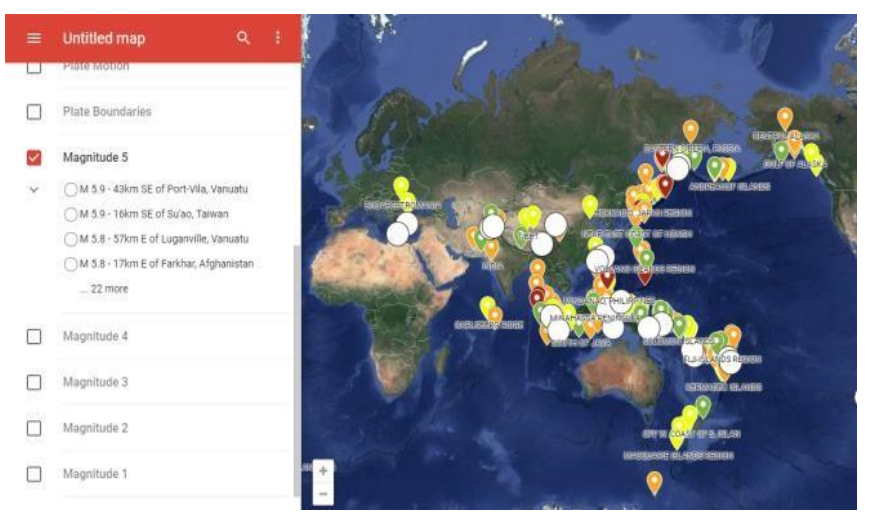

Fig.4 Magnitude greater than 5

\section{CONCLUSION}

This work was centered around creating web services for Tsunami mapping and the information required was gathered from Global CMT Catalog Search from the date of 1976 January 1 to 2019 June 12 . We can conclude that countries at most elevated danger are on the US west coast, Chile, Japan and Pacific islands like the Solomon Islands.

The webpage was created by utilizing HTML, JAVASCRIPT, CSS, and JQuery. By analyzing the created website page the seismic tremor is going on regularly in the Ring of Fire area. Around 190 quakes occurred in the middle of the timespan of 1976 January 1 to 2019 June 12 everywhere throughout the world. This tsunami hazard map webpage is useful to provide early tsunami warning and evacuation of local population and rescueoperations. 


\section{REFERENCE}

[1] 1.TUNAMIFF: https://github.com/tunamiff2011cuda /tunamiff2011

[2] T. Srinivasa Kumar, Ch. Patanjali Kumar, B. Ajay Kumar, Shailesh Nayak, Srinivasulu Mulukutla and Vittal TS, "Geospatial Technology Solution for Indian National Tsunami Early Warning System", Map World Forum, 2009

[3] Shailesh Nayak and T. Srinivasa Kumar, "Addressing the Risk of Tsunami in the Indian Ocean", Journal of South Asia Disaster Studies,

Vol. 1 No. 1 November 2008, 45-57

[4] A Farhan and H Akhyar 2017 IOP Conf. Ser.: Earth Environ. Sci. 56012002

[5] bhadauria, N.; Suresh, A. Adsorptive Removal of Congo red dye from wastewater using Fenugreek Powder. Preprints 2020, 2020040173(doi:10.20944/preprints202004.0173.v1).

[6] Suresh, A. Mystery over the Haze during 1st week of November 2019 in Delhi-NCR. Preprints 2020,2020040156(doi:10.20944/preprints202004.015 6.v1).

[7] Nathalia, Deepa, Arjun Suresh, and Neha Singh. "Monitoring Land Use / Cover Changes during the Mining Activities in Aravalli Hill Region." 3.6 (2018): n. pag. Print.

[8] Bhardwaj, Pallavi et al. "Satellite Monitoring for Spatio-Temporal Changes Occurring in Forest Area of Sariska Tiger Reserve by Implementing GIS and Remote Sensing Techniques.” 10 (2019): 26-36. Print.

[9] Rao, V. K., et al. "Validation of water vapor profiles from INSAT-3D with AIRS retrievals and groundBased measurement over India." Remote Sensing Applications: Society and Environment 15 (2019): 100231.

[10] jose, J., Yuvaraj E., Kushik B., Neha Singh., Suresh A., Global Tsunami Hazard Web Map For Mitigation And Rescue Operation. International journal of scientific \& technology research. (2020) volume 9 , issue 01 